\title{
Labor in pregnancies with small for gestational age suspected fetuses
}

\author{
Damian Warzecha ${ }^{A-D}$, Eliza Kobryñ ${ }^{A-D}$, Marta Bagińska ${ }^{B-D}$, Dorota Bomba-Opon ${ }^{A, E, F}$ \\ $1^{\text {st }}$ Department of Obstetrics and Gynecology, Medical University of Warsaw, Poland \\ A - research concept and design; $B$ - collection and/or assembly of data; $C$ - data analysis and interpretation; \\ $D$ - writing the article; $E$ - critical revision of the article; $F$ - final approval of the article
}

Address for correspondence

Dorota Bomba-Opoń

E-mail: dorota.bomba-opon@wum.edu.pl

Funding sources

None declared

Conflict of interest

None declared

Received on December 16, 2016

Reviewed on February 5, 2017

Accepted on March 7, 2017

\begin{abstract}
Background. Fetal growth restriction (FGR) is an unclearly defined condition described as a fetal weight which is too low in relation to gestational age. It is recognized in 10-15\% of singleton pregnancies and can lead to severe complications, including stillbirth. To reduce the adverse fetal and neonatal outcomes, many medical interventions are being introduced by obstetricians. These, like all medical procedures, may induce further complications, such as preterm labor and its consequences.
\end{abstract}

Objectives. The aim of this study was to assess in terms of perinatal and neonatal outcomes such management procedures as expectant monitoring, induction or elective cesarean section (ECS) in pregnancies where the fetus is suspected of being small for gestational age (SGA). There was also the goal of determining the specificity of ultrasound examination in the recognition of SGA.

Material and methods. The single-center retrospective study was carried out among 146 patients who were prenatally suspected of having SGA pregnancies and who delivered in our hospital. Small for gestational age was defined as estimated fetal weight (EFW) in the $10^{\text {th }}$ percentile or below. The output cohort was divided into 2 subgroups: group A - with antenatally confirmed hypotrophy, and group B - without antenatally confirmed hypotrophy.

Results. Out of 146 newborns suspected of being SGA, 65 had a birth weight in the $10^{\text {th }}$ percentile or below, and the estimated positive predictive value of ultrasound examination amounted to 44.5\%. Underweight mothers correlated with 5 times higher rates of SGA overdiagnosis. Serious neonatal complications, such as neonatal deaths, respiratory or cardiovascular dysfunctions, and admission to the neonatal intensive care unit (NICU), occurred significantly more often in confirmed SGA cases (46\% vs $19 \%$ in group B, with a p-value of $0.0066,0.0253,0.0027$, and 0.0253 , respectively). The highest rate of ECS concerned patients from group A ( $44.6 \%$ vs $30.9 \%$ in unconfirmed samples; $p=0.04$ ), while expectant management was more often associated with neonatal death and admission to the NICU than with elective procedures (18.2\% vs $7.4 \%$ and $36.4 \%$ vs $27.8 \%$, respectively).

Conclusions. Customized charts used during ultrasound examination, which evaluate additional parameters such as body mass index (BMI), may decrease the overdiagnosis of SGA.

Key words: small for gestational age, body mass index, fetal hypotrophy, labor induction, elective procedures

DOI

10.17219/acem/69347

\section{Copyright}

Copyright by Author(s)

This is an article distributed under the terms of the

Creative Commons Attribution Non-Commercial License

(http://creativecommons.org/licenses/by-nc-nd/4.0/) 


\section{Introduction}

Fetal growth restriction (FGR) is a condition unclearly defined as a fetal weight which is too low in relation to gestational age. Different kinds of FGR appear in 5-10\% of all pregnancies. ${ }^{1}$ This multitude of forms is due to different definitions based on diverse diagnostic criteria. Fetal hypotrophy is synonymous with a small fetus which did not fully realize its growth potential. Other disorders, such as "small for gestational age" (SGA) and "intrauterine growth restriction" (IUGR) are diagnosed by ultrasound examination during the $2^{\text {nd }}$ and $3^{\text {rd }}$ trimester of pregnancy. Small for gestational age is defined as estimated fetal weight (EFW) below the $10^{\text {th }}$ percentile in ultrasound examination using a software program which calculates the fetal weight on the basis of particular parameters. ${ }^{2}$ The definition of IUGR is the same as SGA, but there is an additional requirement to evaluate impaired Doppler flows in the umbilical artery or in the medium cerebral artery.

All types of FGR are associated with severe complications, which are a challenge and a substantial problem for contemporary perinatology. The causes of SGA can be constitutional determinants or various pathological factors, but typically a combination of several of them leads to fetal hypotrophy. ${ }^{3}$ Fetal growth restriction is associated with an increased risk of adverse perinatal outcomes, especially stillbirth, preterm delivery, intrauterine hypoxia, cerebral palsy, and other complications in late childhood, as well as lower IQ scores in young adults., ${ }^{4,5}$ Thus, every patient with suspected fetal hypotrophy should be monitored under professional obstetric care.

The problem becomes more complex when regarding the opinions of scientific committees about the standards of management in patients with suspected SGA fetuses. A lack of medical interventions with proven effectiveness, which could stop or reverse the development of FGR, render appropriate perinatal care to be the only therapeutic option. However, there is no unanimity among European and American societies concerning the time and method of delivery. According to the guidelines set forth by the Royal College of Obstetricians and Gynecologists, the essential parameters deciding about the best management are umbilical Dopplers. In fetuses with inappropriate umbilical artery flows (absent or reversed end-diastolic velocity), the committee recommends delivery by cesarean section, while induced labor may be offered to those with normal umbilical artery Doppler flows (with level B evidence) ${ }^{6}$ Canadians suggest that if a pregnancy lasts longer than 37 weeks, the obstetrician should consider the choice between expectant management with close fetal/maternal surveillance and delivery. When undertaking clinical interventions, such as cesarean section, ultrasound assessment is a useful tool in evaluating fetal viability. ${ }^{7}$

On the other hand, the American College of Obstetricians and Gynecologists cites the results from trials such as the Growth Restriction Intervention Trial (GRIT) and the
Disproportionate Intrauterine Growth Intervention Trial At Term (DIGITAT), which proved no benefit or harm caused by immediate delivery. ${ }^{8}$

According to the Polish Gynecological Society's guidelines, induced labor is recommended in such cases. ${ }^{9}$ There is research proving that SGA recognized antenatally implicates more frequent obstetric interventions, without a significant positive impact on early neonatal outcomes. ${ }^{10}$

\section{Objectives}

The study aimed to assess different kinds of management (expectant monitoring, induction or elective cesarean section - ECS) in pregnancies with suspected SGA fetuses in the context of perinatal outcomes and neonatal complications. The other purpose was to determine the specificity of ultrasound examination in recognizing SGA.

\section{Material and methods}

This retrospective single-center study was carried out in the $1^{\text {st }}$ Department of Obstetrics and Gynecology at the Medical University of Warsaw, Poland. Data regarding the baseline characteristics of patients and the course of gestation was obtained from archival medical documentation of hospitalizations during the last pregnancy. The inclusion criteria were women in singleton pregnancies suspected of fetal hypotrophy or SGA who delivered in the $25^{\text {th }}-41^{\text {st }}$ week of gestation between January 1, 2013 and December 31, 2014. The exclusion criteria were insufficient or incomplete medical history (usually associated with missing ultrasound scans), women in multiple pregnancies and fetuses with chromosomal abnormalities. The study group consisted of 146 patients, according to the abovementioned criteria.

The authors also evaluated the following complications during pregnancy: gestational hypertension, preeclampsia, diabetes, oligohydramnios (defined as an amniotic fluid index - AFI $<5 \mathrm{~cm}$ after summing up the measurements of the largest fluid pockets from each of the 4 uterine quadrants), and obesity (body mass index - BMI $\left.\geq 30 \mathrm{~kg} / \mathrm{m}^{2}\right){ }^{11-13}$ Other parameters, such as maternal age, parity and smoking during pregnancy, were also taken into consideration. The authors also carefully took into account complications in previous pregnancies - especially stillbirth, IUGR and preeclampsia.

The study group comprised 146 women in singleton pregnancies with suspected SGA. Small for gestational age was defined as a fetus with EFW below the $10^{\text {th }}$ percentile for adequate gestational age, using standard population-based centile charts. Estimated fetal weight was assessed through ultrasound examination during the $3^{\text {rd }}$ trimester, based on the following biometric measurements: bi-parietal diameter (BPD), head circumference 
(HC), abdominal circumference (AC), and femur length (FL), using the Hadlock-1 formula (BPD + $\mathrm{HC}+\mathrm{AC}+$ FL) developed by Professor Kypros Nicolaides. Many research studies have proven the utility of this formula with a high positive correlation between EFW and actual birth weight. ${ }^{14,15}$ Also, in comparison with other available patterns, it seems to have the highest predictive value. ${ }^{16}$ The authors took into account only the outcome of the recent ultrasound examination which confirmed SGA. Each ultrasound examination was carried out at the hospital ultrasonography station, using high-quality ultrasound systems with a curvilinear array real-time system and a 3.5 or $5.0 \mathrm{MHz}$ transducer.

From the cohort of 146 patients with suspected SGA fetuses, the authors retrospectively selected a group of patients with hypotrophy of the fetuses confirmed after delivery, hereafter called group A. Neonatal hypotrophy was defined as a newborn's birth weight below the $10^{\text {th }}$ percentile for the appropriate week of delivery, sex and population. Patients with false positive diagnosis of SGA, unconfirmed after delivery, were classified as group $\mathrm{B}$.

Both groups were compared between each other with regard to the average duration of gestation, the percentage of preterm births, the mother's age, BMI, and parity - and in the cases of multiparous women, the time since the previous pregnancy. All patients were of Caucasian ethnicity.

Patients from the study group were evaluated for the mode of delivery, medical procedures undertaken during pregnancy and perinatal complications. The authors assessed whether women from the study group had indications for induced labor or ECS, and what influence these procedures had on the maternal and neonatal outcomes. Adverse neonatal outcomes were defined as death before hospital discharge, a 5-minute Apgar score $<7$ and admission to the neonatal intensive care unit (NICU). In perinatal complications, the authors also evaluated the length of stay at the NICU or the neonatal ward, respiratory disorders, sepsis, hypoglycemia, and intraventricular hemorrhage.

The outcomes were analyzed with regard to double cutoff thresholds for both the study group and the control group: $<10^{\text {th }}-3^{\text {rd }}$ percentile and $<3^{\text {rd }}$ percentile.

Statistical analysis was performed with the Mann-Whitney $U$ test for qualitative values and the Fisher's exact test in the case of quantitative references. P-values $<0.05$ were considered significant. For a statistical evaluation of the results obtained, the authors used the Statistical Analysis Statement program (SAS/STAT ${ }^{\circledR}$ v. 14.1 Software, SAS Institute Inc., Cary, USA).

\section{Results}

Sixty-five newborns suspected of being SGA antenatally by ultrasound examination had a birth weight below the $10^{\text {th }}$ percentile, which represents $44.5 \%$ of the sample size. Eighty-one patients (55.5\%) were not confirmed as SGA after delivery (later defined as group B). The accordingly positive predictive value of ultrasound examination in the recognition of SGA was estimated at $44.5 \%$. Within group A, the mean age of the mothers equaled 32.5 years $( \pm 5.05)$ and was significantly higher than the mean age within group $B$, which was 29.5 years $( \pm 5.69)$ $(\mathrm{p}=0.0015)$. The percentage of primiparous women was lower among patients whose newborns were diagnosed as SGA after birth, but without statistical significance $(62 \%$ vs $74 \%$ in group $\mathrm{B} ; \mathrm{p}=1.0$ ). When it comes to multiparous women, the time elapsed since their last pregnancy was similar in both groups $(1.74 \pm 4.89$ years vs $1.72 \pm 2.83$ years in groups $\mathrm{A}$ and $\mathrm{B}$, respectively; $\mathrm{p}=0.3496$ ).

The average duration of pregnancy was lower among patients from the $1^{\text {st }}$ group and equaled $34.9 \pm 3.80$ weeks, in comparison to $36.9 \pm 2.55$ weeks in the $2^{\text {nd }}$ one $(\mathrm{p}=0.0317)$.

Among all mothers, $58.9 \%$ delivered between the $37^{\text {th }}$ and the $41^{\text {st }}$ week of pregnancy, $40.4 \%$ before the $37^{\text {th }}$ week and $0.7 \%$ of the pregnancies lasted over 41 weeks. Late-preterm deliveries (between the $34^{\text {th }}$ and the $36^{\text {th }}$ week) made up $23.3 \%$ of all pregnancies, while early-preterm (before the $34^{\text {th }}$ week) constituted $17.1 \%$ of the sample size. The full characteristics of patients are presented in Table 1.

The average BMI value at the beginning of the pregnancy was $23.38 \pm 4.38 \mathrm{~kg} / \mathrm{m}^{2}$ in patients with SGA confirmed after delivery, while in group B, the mean BMI was $21.97 \pm 4.26 \mathrm{~kg} / \mathrm{m}^{2}$. A retrospective analysis evaluating BMI values in comparison with a positive predictive value of SGA recognition during antenatal ultrasound examination was also conducted. Patients from the study group were divided into 3 subgroups depending on BMI values, namely: $<18.5 \mathrm{~kg} / \mathrm{m}^{2}$, between $18.5 \mathrm{~kg} / \mathrm{m}^{2}$ and $25 \mathrm{~kg} / \mathrm{m}^{2}$, and $>25 \mathrm{~kg} / \mathrm{m}^{2}$ (Table 2). Maternal underweight $\left(\mathrm{BMI}<18.5 \mathrm{~kg} / \mathrm{m}^{2}\right)$ correlated with only an $11 \%$ positive predictive value of SGA recognition in ultrasound

Table 1. Baseline characteristics of groups

\begin{tabular}{|c|c|c|c|}
\hline Parameter & Group A & Group B & $\mathrm{p}$-value \\
\hline Sample size & 65 & 81 & - \\
\hline $\begin{array}{l}\text { Percentage of the study } \\
\text { group }\end{array}$ & $44.5 \%$ & $55.5 \%$ & - \\
\hline $\begin{array}{l}\text { The mothers' mean age } \\
\text { [years] }\end{array}$ & $32.5 \pm 5.05$ & $29.5 \pm 5.69$ & $0.0015^{*}$ \\
\hline $\begin{array}{l}\text { Percentage } \\
\text { of primiparous women }\end{array}$ & $62 \%$ & $74 \%$ & 1.000 \\
\hline $\begin{array}{l}\text { Mean time since last } \\
\text { pregnancy [years] }\end{array}$ & $1.74 \pm 4.89$ & $1.72 \pm 2.83$ & 0.3496 \\
\hline $\begin{array}{l}\text { Mean duration } \\
\text { of pregnancy [weeks] }\end{array}$ & $34.9 \pm 3.80$ & $36.9 \pm 2.55$ & $0.0317^{*}$ \\
\hline Average BMI $\left[\mathrm{kg} / \mathrm{m}^{2}\right]$ & $23.38 \pm 4.38$ & $21.97 \pm 4.26$ & $0.0208^{*}$ \\
\hline
\end{tabular}

Group A - group with a confirmed diagnosis of small for gestational age (SGA) after delivery; group B - group without a confirmed diagnosis of SGA after delivery; BMI - body mass index; * statistically significant. 
Table 2. Percentage of confirmed SGA diagnoses after birth according to the patients' BMI before pregnancy

\begin{tabular}{|l|c|}
\multicolumn{1}{|c|}{$\begin{array}{c}\text { BMI }\left[\mathrm{kg} / \mathrm{m}^{2}\right] \\
\text { before pregnancy }\end{array}$} & $\begin{array}{c}\text { Percentage of confirmed } \\
\text { diagnoses of SGA after delivery }\end{array}$ \\
\hline$\leq 18.49$ & $11 \%$ \\
\hline $18.5-24.99$ & $49 \%$ \\
$\geq 25$ & $46 \%$ \\
\hline
\end{tabular}

$\mathrm{BMI}$ - body mass index; SGA - small for gestational age.

examination $(\mathrm{p}=0.0051)$. The results obtained show that up to $89 \%$ of pregnancies were overdiagnosed and that in that group, the standard methods of SGA recognition are less efficient. The percentage of confirmed SGA fetuses after birth was similar in women with normal weight (BMI of between $18.5 \mathrm{~kg} / \mathrm{m}^{2}$ and $25 \mathrm{~kg} / \mathrm{m}^{2}$ ) and those who were obese before pregnancy $\left(\mathrm{BMI}>25 \mathrm{~kg} / \mathrm{m}^{2}\right)$, and it amounted to $49 \%$ and $46 \%$, respectively.

Body mass index evaluated in the last trimester of pregnancy had no significant influence on the detection of SGA babies.

Among all patients, 59 gestations were complicated, with preterm delivery. In that group, $42.4 \%$ of samples (25) were classified as early preterm (defined as labor between the $22^{\text {nd }}$ and the $34^{\text {th }}$ week of gestation), while $57.6 \%$ (34) were late preterm deliveries (between weeks 35 and 37). With a view to generating more precise results, we decided to isolate a group of severe hypotrophy with EFW below the $3^{\text {rd }}$ percentile. In the $1^{\text {st }}$ group, $84 \%$ of newborns were classified below the $3^{\text {rd }}$ percentile after birth and $16 \%$ of them were between the $3^{\text {rd }}$ and $9.9^{\text {th }}$ percentile. In the case of late preterm delivery, the percentage of newborns below the $3^{\text {rd }}$ percentile was lower than in the previous group and amounted to $53 \%$, while $47 \%$ of them gained in birth weight from the $3^{\text {rd }}$ to the $9.9^{\text {th }}$ percentile.

Patients who underwent iatrogenic procedures comprised $86.3 \%$ of all pregnancies (126). Up to $43 \%$ (54) of those pregnancies were ended by ECS and $57 \%$ (72) by induced labor. Induced deliveries ended with ECS in $23.6 \%$ of cases. Of all deliveries, $13.7 \%$ (20) began spontaneously, where $65 \%$ (13) were managed by vaginal delivery and 35\% (7) required cesarean section. The most frequently isolated medical indication for induced labor was fetal hypotrophy (about 50\%). In $37.5 \%$ of all patients, the suspicion of SGA occurred together with several other indications, such as post-term pregnancy, oligohydramnios, gestational diabetes mellitus, pregnancy-induced hypertension, and abnormalities in a non-stress test. Only $12.5 \%$ of all cases were associated with indications other than fetus hypotrophy, e.g., preeclampsia or preterm rupture of membranes.

The most severe complication - intrauterine death - occurred in 2 cases in group A ( $3 \%$ of the sample), while it was not reported among group $B$. The risk of intrauterine death did not significantly correlate with any pathologies during the course of pregnancy, including IUGR ( $p=0.196)$.
In each case, the prenatal diagnosis of SGA was confirmed after delivery with a neonatal birth weight below the $1^{\text {st }}$ percentile (418 g and $880 \mathrm{~g}$ ). Both of those pregnancies ended with vaginal delivery, the $1^{\text {st }}$ one spontaneously in the $27^{\text {th }}$ week, while the $2^{\text {nd }}$ one ended after induction and steroid therapy in the $31^{\text {st }}$ week of pregnancy due to the threat of asphyxia.

In total, 78 pregnancies ended with cesarean section - in $69 \%$ as an elective procedure, in $22 \%$ after an unsuccessful induction and in $9 \%$ following a spontaneously begun delivery. Most of them were associated with the following indications: imminent fetal asphyxia, fetal hypotrophy, abnormal outcome of a non-stress test, failed induction, and breech position or preeclampsia.

The Apgar score, the simplest and most reliable method of evaluation, was performed to assess the general condition of newborn babies suspected of being SGA. We observed significantly worse perinatal outcomes in the group with confirmed severe hypotrophy (below the $3^{\text {rd }}$ percentile). Of those newborns, $17.6 \%$ scored $<7$ points and $8.8 \%$ scored $<3$ points in the Apgar score in the $1^{\text {st }}$ minute, while only $4.5 \%$ of the infants between the $3^{\text {rd }}$ and $9.9^{\text {th }}$ percentile in weight scored $<7$ points $(\mathrm{p}=0.0213)$.

For 13 newborns from the output cohort, medical documentation was unavailable, which is why the following outcomes regard a smaller sample size than before, 59 samples with confirmed hypotrophy (group A) and 74 without confirmation after delivery (group B).

Serious complications in the early neonatal period, e.g., respiratory disorders, cardiovascular insufficiency, intraventricular hemorrhage, or neonatal deaths, occurred in $34 \%$ (45) of all newborns whose medical history was available, and separating that data, in $46 \%$ and $19 \%$ of samples from groups A and B, respectively.

Elective cesarean section was performed in $68.4 \%$ of patients from group A and in $63.2 \%$ of group B patients, respectively; induced labor was executed in $10.5 \%$ of patients from group A and in $21.1 \%$ from group B.

Newborns with confirmed hypotrophy were more often admitted to the NICU after birth (32.2\% vs $23 \%$; $\mathrm{p}=0.0253)$ and significantly more frequently suffered from cardiovascular insufficiency (18.6\% vs $2.7 \%$; $\mathrm{p}=0.0027)$. Moreover, children from group A more often required invasive procedures, such as synchronized intermittent mandatory ventilation (SIMV) (18.6\% vs 5.4\%; $\mathrm{p}=0.0253)$. We reported 6 neonatal deaths after delivery in group A (10.2\%), while that complication was not observed among any neonates with an unconfirmed diagnosis of SGA ( $p=0.0066)$. More details concerning severe neonatal complications are presented in Table 3.

The complications which occurred in the remaining newborns, such as intraventricular hemorrhage, early infections and hypoglycemia, did not demonstrate any statistically significant correlations. The average duration of hospitalization was similar in both groups $(8.67 \pm 9.81$ days vs $7.86 \pm 8.80$ days; $\mathrm{p}=0.2365$ ). 
Table 3. Percentage of neonatal complications among the studied groups

\begin{tabular}{|l|c|c|c|c|}
\hline \multicolumn{1}{|c|}{ Complication } & Total & Group A & Group B & p-value \\
\hline Neonatal deaths & $4.5 \%$ & $10.2 \%$ & $0.0 \%$ & $0.0066^{*}$ \\
\hline NICU hospitalization & $27.1 \%$ & $32.2 \%$ & $23.0 \%$ & $0.0253^{*}$ \\
\hline $\begin{array}{l}\text { Respiratory dysfunction: } \\
\text { CPAP }\end{array}$ & $7.5 \%$ & & & 0.0511 \\
SIMV & $11.3 \%$ & $18 \%$ & $0.0253^{*}$ \\
\hline Cardiovascular insufficiency & $9.8 \%$ & $18.6 \%$ & $5.4 \%$ & $0.0027^{*}$ \\
\hline Intraventricular hemorrhage & $14.3 \%$ & $18.6 \%$ & $2.7 \%$ & 0.2211 \\
\hline Hypoglycemia & $19.5 \%$ & $11.9 \%$ & $10.1 \%$ & 0.0508 \\
\hline Infection & $23.3 \%$ & $27.1 \%$ & $25.7 \%$ & 0.4113 \\
\hline Average hospitalization time [days] & $8.13 \pm 9.22$ & $8.67 \pm 9.81$ & $20.3 \%$ & 0.2365 \\
\hline
\end{tabular}

Group A - group with a confirmed diagnosis of small for gestational age (SGA) after delivery; group B - group without a confirmed diagnosis of SGA after delivery; NICU - neonatal intensive care unit; CPAP - continuous positive airway pressure; SIMV - synchronized intermittent mandatory ventilation;

* statistically significant.

Table 4. Correlation between neonatal complications and methods of management

\begin{tabular}{|c|c|c|c|}
\hline Variable & Group A & Group B & $\mathrm{p}$-value \\
\hline Total amount & 65 & 81 & $\begin{array}{c}\text { comparison between both } \\
\text { groups }\end{array}$ \\
\hline $\begin{array}{l}\text { Induced labor } \\
\text { - NICU hospitalization } \\
\text { - newborn deaths }\end{array}$ & $\begin{array}{l}38.5 \%(25) \\
8.0 \%(2) \\
4.0 \%(1)\end{array}$ & $\begin{array}{c}58.0 \%(47) \\
8.5 \%(4) \\
0 \%\end{array}$ & $\begin{array}{l}0.0208^{*} \\
0.6726 \\
0.4452\end{array}$ \\
\hline $\begin{array}{l}\text { Elective C-section } \\
\text { - NICU hospitalization } \\
\text { - newborn deaths }\end{array}$ & $\begin{array}{c}44.6 \%(29) \\
44.8 \%(13) \\
10.3 \%(3)\end{array}$ & $\begin{array}{l}30.9 \%(25) \\
48.0 \%(12) \\
\quad-\end{array}$ & $\begin{array}{l}0.0400^{*} \\
0.5083 \\
0.0860\end{array}$ \\
\hline $\begin{array}{l}\text { Spontaneous vaginal delivery } \\
\text { - NICU hospitalization } \\
\text { - newborn deaths }\end{array}$ & $\begin{array}{l}16.9 \%(11) \\
36.4 \%(4) \\
18.2 \%(2)\end{array}$ & $\begin{array}{c}11.1 \%(9) \\
33.3 \%(3) \\
0 \%\end{array}$ & $\begin{array}{l}0.3408 \\
0.7003 \\
0.1965\end{array}$ \\
\hline $\begin{array}{l}\text { Elective delivery (induced labor + C-section) } \\
\text { - NICU hospitalization } \\
\text { - newborn deaths }\end{array}$ & $\begin{array}{l}83.1 \%(54) \\
27.8 \%(15) \\
7.4 \%(4)\end{array}$ & $\begin{array}{c}88.9 \%(72) \\
22.2 \%(16) \\
0 \%\end{array}$ & $\begin{array}{l}0.3408 \\
0.6861 \\
0.0373^{*}\end{array}$ \\
\hline
\end{tabular}

Group A - group with a confirmed diagnosis of small for gestational age (SGA) after delivery; group B - group with an unconfirmed diagnosis of SGA after delivery; NICU - neonatal intensive care unit; C-section - cesarean section; ${ }^{*}$ statistically significant.

Hospitalization at the NICU was required in $8 \%$ and $8.5 \%$ of newborns after induced labor ( $\mathrm{p}=0.6726)$, in $45 \%$ and $48 \%$ of those delivered by ECS ( $\mathrm{p}=0.5083$ ), and in $36 \%$ and $33 \%$ of children after spontaneous vaginal birth $(\mathrm{p}=0.7)$ in groups A and B, respectively.

In accordance with the method of management (Table 4), we found the highest rate of ECS among patients with confirmed hypotrophy after delivery (44.6\% vs $30.9 \%$ in the unconfirmed group; $\mathrm{p}=0.04$ ). That mode of delivery was also most frequent among mothers from group A. The percentage of induced labor cases was the highest in patients with unverified SGA and equaled $58 \%$ vs $38.5 \%$ in group A ( $\mathrm{p}=0.0208)$. Both groups are characterized by a similar percentage of elective procedures (induction and cesarean section altogether), measured at $83.1 \%$ (A) and $88.9 \%$ (B) with a p-value of 0.3408 . A decidedly less frequently reported method of delivery in the studied group was spontaneous vaginal delivery, without a significant difference between groups A and B (16.9\% vs 11.1\%; $\mathrm{p}=0.3408)$.

Expectant management in both groups led to worse perinatal outcomes than elective procedures performed to prevent fetal complications.
From a different perspective, dividing the groups into severe (below the $3^{\text {rd }}$ percentile) and mild ( $3^{\text {rd }}-9.9^{\text {th }}$ percentile) hypotrophy, serious complications occurred in $62 \%$ and $38 \%$ of newborn babies, respectively (Fig. 1).

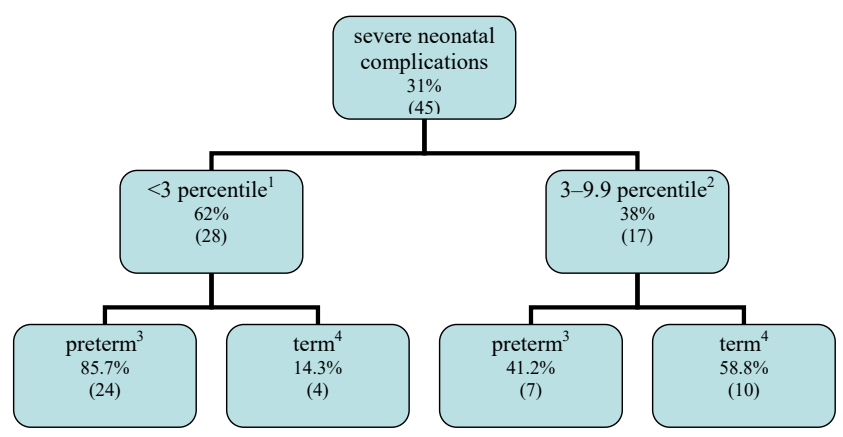

Fig. 1. Percentage of severe neonatal complications classified depending on the percentile of newborn weight and time of birth

1 - newborns birth weight under $3^{\text {rd }}$ percentile; 2 - newborns birth weight between $3^{\text {rd }}$ to 9.9 percentile; 3 - percentage of severe neonatal complications among preterm births; 4 - percentage of severe neonatal complications among at term births. 


\section{Discussion}

In this study, the estimated positive predictive value of ultrasound examination in the recognition of SGA during late pregnancy was $44.5 \%$. This data is similar to the findings from a large population-based study on French pregnant women, where $1 / 2$ of all infants suspected of FGR were not confirmed after delivery. ${ }^{17}$

To the best of our knowledge, there are limited studies which ex post facto evaluate the correlation between different variables and their influence on making a correct or false positive diagnosis of SGA. The available clinical data is very limited and precludes any reliable conclusion in that area.

According to our study, mothers with SGA babies confirmed after delivery were significantly older than those with the false positive diagnosis (mean age of 32.5 years in group A; $\mathrm{p}=0.0015$ ). Early motherhood is considered a risk factor for lower birth weight in newborns, while advanced age seems to increase the frequency of SGA only in primiparous women. ${ }^{18,19}$

Apart from that, a longer duration of pregnancy and advanced gestational age at the time of delivery $(36.9 \pm 2.55$ weeks vs $34.9 \pm 3.80$ weeks in confirmed cases) correlate with a higher incidence of incorrect antenatal diagnoses $(\mathrm{p}=0.0317)$.

Interesting conclusions can be drawn when it comes to the comparison of the positive predictive value of ultrasound examination with the mothers' BMI values at the beginning of pregnancy.

Underweight mothers (BMI $<18.5 \mathrm{~kg} / \mathrm{m}^{2}$ ) correlate with nearly 5 times more frequent overdiagnosis of SGA in comparison to BMI values between $18.5 \mathrm{~kg} / \mathrm{m}^{2}$ and $25 \mathrm{~kg} / \mathrm{m}^{2}$, and $>25 \mathrm{~kg} / \mathrm{m}^{2}$ (11\% of correct diagnoses vs $49 \%$ and $46 \%$ in the remaining groups, respectively; $\mathrm{p}=0.0051$ ). In that group, only $11 \%$ of the fetuses suspected antenatally of being SGA were confirmed as hypotrophic fetuses after birth. Lower maternal initial BMI values seem to be associated with impaired EFW assessment. The phenomenon described above may be related to the influence of certain constitutive factors.

There is substantial evidence in the literature which proves that petite women, especially those underweight before pregnancy, give birth to smaller babies. ${ }^{20}$ On the other hand, a recently published vast meta-analysis provides evidence that short maternal stature and chronic malnutrition, especially in developing countries, contribute to a higher incidence of SGA. ${ }^{21}$ It is hard to draw clear conclusions if that diagnosis is connected to inter-subject variability or the damaging influence of exogenous factors.

More often, the overdiagnosis of SGA babies in women with lower BMI before pregnancy seems to confirm that most of those cases are likely associated with genetic factors rather than pathological intrauterine growth retardation. Such hypotheses were also presented by previous researchers, who concluded that a generational transmission of SGA is possible. ${ }^{22}$
In this situation, it is worth considering the usefulness of customized charts during ultrasound examination in pregnant women, rather than standard population-based ones. ${ }^{23}$ It has been proven that for SGA suspected antenatally, using customized growth potential is able to identify substantially more pregnancies at risk for adverse outcomes than the currently used national standard for fetal growth. ${ }^{24}$ Recently, the authors of a multi-center project called INTERGROWTH-21 $1^{\text {st }}$, which included 13,108 pregnant women, created fetal growth curves with regard to 5 basic ultrasound measurements. The utility of those charts was positively evaluated in different populations and it may offer precise assessment of intrauterine fetal growth before the customized charts become available. ${ }^{25}$

Such factors as the mother's age, the duration of pregnancy, parity, or the time elapsed since the previous delivery seem not to correlate with a true or false positive diagnosis of SGA.

The most severe complication in the course of pregnancy - intrauterine death - occurred 2 times in group A, while it was not reported among patients from group B. However, the risk of intrauterine death was not significantly correlated with any pathologies during the course of pregnancy, including IUGR ( $p=0.196)$, though this may result from the small sample size.

Aware of fetal complications, obstetricians decide to induce labor, while this procedure is not without consequences.

The multi-center randomized trial, DIGITAT, comparing both types of managements (induction and expectant monitoring), provided similar efficacy regarding perinatal outcomes. Despite this, the researchers found that induced labor seems to be a more rational method of management which reduces the risk of stillbirth and newborn morbidity. ${ }^{26}$

In this study, the estimated percentage of ECSs among true-positives amounted to $44.6 \%$ and was twice as high as that from the previously described study on the French population (44.6\% vs $23.8 \%$ ), while the ECSs in false-positives were carried out with similar frequency $(30.9 \%$ vs $28.4 \%$ in the French study). ${ }^{17}$

Stricter indications for elective procedures and more appropriate recognition of FGR could prevent the side effects of unnecessary medical interventions in the future.

In the context of the final neonatal outcomes, the current study shows that expectant management can increase the percentage of neonatal complications; the best indicators of that are the number of neonates hospitalized in the NICU and neonatal deaths. Elective delivery - labor induction or ECS - despite the risk of these invasive procedures, could minimize adverse neonatal outcomes in patients with suspected fetal hypotrophy.

In contrast, previous longitudinal studies on pregnant women with suspected FGR suggest that a higher incidence of obstetric interventions does not entail demonstrable positive effects upon short-term neonatal outcomes. ${ }^{27}$ Moreover, induction of labor seems to be associated with 
a higher rate of adverse neonatal outcomes. ${ }^{28,29}$ Evidence on the best management strategy for at term IUGR, when it comes to perinatal outcomes, is still lacking. ${ }^{30}$

This difficult decision between elective procedure and expectant management should always be taken by an experienced obstetrician, with careful consideration of the advantages and disadvantages of both methods. It is hard to draw an explicit conclusion about which form of management could be better, and in each case, all conditions should be individually assessed.

There are several limitations of this study that should be considered along with the results.

First of all, the selected study group is from a single-center study, conducted in a tertiary medical center unit. At baseline, most patients underwent more than 1 diagnosis, which makes it hard to compare them to the standard population.

On the other hand, the cohort of patients with confirmed SGA after delivery accounted for only 65 cases. In such limited study group, it is hard to draw unmistakable correlations between different factors and their influence on the occurrence of SGA. More research on a larger group of patients with confirmed SGA is required.

Secondly, as mentioned before, the measurements which were the basis for diagnosing SGA were taken by several ultrasonography technicians. Aberrations caused by human error cannot be excluded, and they may impact the reproducibility of the results between sequential ultrasound examinations.

The assessment of SGA was set only based on EFW below the $10^{\text {th }}$ percentile. On the other hand, there are some studies which prove that evaluating artery flow with fetal biometry aids in identifying the babies at risk of IUGR. Such a procedure may decrease the number of antenatal false positive diagnoses of SGA in the future.

\section{Conclusions}

Creating customized percentile charts which could be correlated with other additional parameters, such as the patient's BMI, may decrease the overdiagnosis of SGA when using ultrasound imaging in the future. Stricter indications for the induction of labor would prevent unnecessary medical procedures and their side effects. However, expectant management leads to worse perinatal outcomes, defined as a higher rate of neonate death or required NICU treatment, than elective procedures.

With the goal of better neonatal outcomes, it seems more rational to choose elective management in patients suspected of being SGA, indeed, if that diagnosis is characterized by sufficient reliability.

\section{References}

1. Thompson JL, Kuller JA, Rhee EH. Antenatal surveillance of fetal growth restriction. Obstet Gynecol Surv. 2012;67(9):554-565. doi: 10. 1097/OGX.0b013e31826a5c6f

2. Dashe JS, McIntire DD, Lucas MJ, Lenovo KJ. Effects of symmetric and asymmetric fetal growth on pregnancy outcomes. Obstet Gynecol. 2000;96(3):321-327.

3. De Jong CLD, Francis A, van Geijn HP, Gardosi J. Fetal growth rate and adverse perinatal events. Ultrasound Obstet Gynecol. 1999;13:86-89.

4. Løhaugen GC, Østgård HF, Andreassen S, et al. Small for gestational age and intrauterine growth restriction decreases cognitive function in young adults. J Pediatr. 2013;163(2):447-453.

5. Østgård HF, Skranes J, Martinussen M, et al. Neuropsychological deficits in young adults born small-for-gestational age (SGA) at term. J Int Neuropsychol Soc. 2014;20(3):313-323.

6. Royal College of Obstetricians and Gynaecologists (RCOG). The investigation and management of the small-for-gestational-age fetus. London, UK: Royal College of Obstetricians and Gynaecologists (RCOG); 2013:34 (Green-top Guideline No. 31).

7. Lausman A, Kingdom J; Maternal Fetal Medicine Committee. Intrauterine growth restriction: Screening, diagnosis, and management. J Obstet Gynaecol Can. 2013;35(8):741-748.

8. American College of Obstetricians and Gynecologists (ACOG). ACOG Practice bulletin No. 134: fetal growth restriction. Obstet Gynecol. 2013; 121(5):1122-1133.

9. Rekomendacje zespołu ekspertów Polskiego Towarzystwa Ginekologicznego dotyczące opieki okołoporodowej i prowadzenia porodu. Ginekol Pol. 2009;80:548-557.

10. Ohel G, Ruach M. Perinatal outcome of idiopathic small for gestational age pregnancies at term: The effect of antenatal diagnosis. Int J Gynaecol Obstet. 1996;55(1):29-32.

11. Phelan JP, Smith CV, Broussard P, Small M. Amniotic fluid volume assessment with the four-quadrant technique at 36-42 weeks' gestation. J Reprod Med. 1987;32:540-542.

12. Shanks A, Tuuli M, Schaecher C, Odibo AO, Rampersad R. Assessing the optimal definition of oligohydramnios associated with adverse neonatal outcomes. J Ultrasound Med. 2011;30:303-307.

13. Ogden CL, Carroll MD, Fryar CD, Flegal KM. Prevalence of obesity among adults and youth: United States, 2011-2014. NCHS. Data brief, no 219. Hyattsville, MD: National Center for Health Statistics; 2015. https://www.cdc.gov/nchs/data/databriefs/db219.pdf. Accessed January 10, 2016.

14. Basha AS, Abu-Khader IB, Qutishat RM, Amarin ZO. Accuracy of sonographic fetal weight estimation within 14 days of delivery in a Jordanian population using Hadlock formula 1. Med Princ Pract. 2012;21(4): 366-369.

15. Geerts $L$, Widmer T. Which is the most accurate formula to estimate fetal weight in women with severe preterm preeclampsia? J Matern Fetal Neonatal Med. 2011;24(2):271-279.

16. Esinler D, Bircan O, Esin S, et al. Finding the best formula to predict the fetal weight: Comparison of 18 formulas. Gynecol Obstet Invest. 2015;80(2):78-84.

17. Monier I, Blondel B, Ego A, Kaminiski M, Goffinet F, Zeitlin J. Poor effectiveness of antenatal detection of fetal growth restriction and consequences for obstetric management and neonatal outcomes: A French national study. BJOG. 2015;122(4):518-527.

18. Cooper LG, Leland NL, Alexander G. Effect of maternal age on birth outcomes among young adolescents. Soc Biol. 1995;42(1-2):22-35.

19. Schimmel MS, Bromiker R, Hammerman C, et al. The effects of maternal age and parity on maternal and neonatal outcome. Arch Gynecol Obstet. 2015;291(4):793-798.

20. Belogolovkin V, Alio AP, Mbah AK, Clayton HB, Wathington D, Salihu HM. Patterns and success of fetal programming among women with low and extremely low pre-pregnancy BMI. Arch Gynecol Obstet. 2009;280(4):579-584.

21. Kozuki N, Katz J, Lee AC, et al.; Child Health Epidemiology Reference Group Small-for-Gestational-Age/Preterm Birth Working Group. Short maternal stature increases risk of small-for-gestational-age and preterm births in low- and middle-income countries: Individual participant data meta-analysis and population attributable fraction. J Nutr. 2015;145(11):2542-2550. 
22. Castrillio SM, Rankin KM, David RJ, Collins JW. Small-for-gestational age and preterm birth across generations: A population-based study of Illinois births. Matern Child Health J. 2014;18(10):2456-2464.

23. Stirnemann JJ, Benoist G, Salomon LJ, Bernard JP, Ville Y. Optimal risk assessment of small-for-gestational-age fetuses using 31-34-week biometry in a low-risk population. Ultrasound Obstet Gynecol. 2014; 43(3):311-316.

24. Odibo AO, Francis A, Cahill AG, Macones GA, Crane JP, Gardosi J. Association between pregnancy complications and small-for-gestational-age birth weight defined by customized fetal growth standard versus a population-based standard. J Matern Fetal Neonatal Med. 2011;24(3):411-417.

25. Papageorghiou AT, Ohuma EO, Altman DG, et al.; International Fetal and Newborn Growth Consortium for the $21^{\text {st }}$ Century (INTERGROWTH-21 $1^{\text {st }}$ ). International standards for fetal growth based on serial ultrasound measurements: The fetal growth longitudinal study of the INTERGROWTH-21 ${ }^{\text {st }}$ project. Lancet. 2014;384(9946):869-879.
26. Boers $\mathrm{KE}$, Bijlenga $\mathrm{D}, \mathrm{Mol} \mathrm{BWJ}$, et al. Disproportionate Intrauterine Growth Intervention Trial At Term: DIGITAT. BMC Pregnancy Childbirth. 2007;7:12. doi: 10.1186/1471-2393-7-12

27. Ohel G, Ruach M. Perinatal outcome of idiopathic small for gestational age pregnancies at term: The effect of antenatal diagnosis. Int J Gynaecol Obstet. 1996;55(1):29-32.

28. Kramer MS, Demissie K, Yang H, Platt HR, Sauve R, Liston R. The contribution of mild and moderate preterm birth to infant mortality. J Am Podiatr Med Assoc. 2000;284(7):843-849.

29. Tomashek KM, Shapiro-Mendoza CK, Davidoff MJ, Petrini JR. Differences in mortality between late-preterm and term singleton infants in the United States, 1995-2002. J Pediatr. 2007;151(5):450-456.

30. Boers KE, van der Post JA, Mol BW, van Lith JM, Scherjon SA. Labour and neonatal outcome in small for gestational age babies delivered beyond 36+0 weeks: A retrospective cohort study. J Pregnancy. 2011. doi: $10.1155 / 2011 / 293516$ 